\title{
OPTIMALISASI LAYANAN BIMBINGAN DAN KONSELING MENGGUNAKAN APLIKASI HALLO BK
}

\author{
LISTIYA DEWI YUNIAR \\ SMA Negeri 6 Tasikmalaya \\ e-mail: listiyadewi87@gmail.com
}

\begin{abstract}
ABSTRAK
Layanan Bimbingan dan Konseling berbasis teknologi informasi sangatlah dibutuhkan terutama di zaman revolusi industri 4.0 sekarang ini. Apalagi di saat pandemi covid-19 dimana terbatasnya ruang dan waktu serta adanya kebijakan pemerintah untuk memberlakukan pembelajaran jarak jauh (PJJ) sangat diperlukan sebuah inovasi untuk dapat memfasilitasi layanan Bimbingan dan Konseling bagi peserta didik. Untuk mencapai perkembangan yang optimal, peserta didik tentunya membutuhkan berbagai peran dari pihak sekolah, termasuk guru bimbingan dan konseling (BK). Dalam layanan bimbingan dan konseling peneliti membuat inovasi layanan yang diberikan nama aplikasi Hallo BK. Di dalam aplikasi ini berisikan mengenai menú-menu yang telah di sesuaikan dengan tugas dan fungsi guru BK, serta berbagai layanan Bimbingan dan Konseling yang tetap menjunjung tinggi asas Bimnbingan dan Konseling. Metode penelitian yang digunakan adalah metode kualitatif dengan cara mengukur tingkat kepuasan peserta didik serta telaah dari berbagai bidang seperti Tim manajemen sekolah, guru mata pelajaran, guru Bimbingan dan Konseling, orangtua peserta didik, serta peserta didik. Berdasarkan hasil penelitian diperoleh data tingkat kepuasan peserta didik yakni bagi kelas XII tingkat kepuasan Layanan BK Mencapai 97,2\%, peserta didik kelas XI mencapai angka 95,7\%, dan bagi peserta didik kelas X tingkat kepuasan mencapai angka 98,4\%. Sehingga dapat disimpulkan jika layanan bimbingan dan konseling menggunakan aplikasi Hallo BK sangat lah efektif dan pengguna sebagian besar merasa puas terhadap layanan yang diberikan.
\end{abstract}

Kata Kunci : Aplikasi Hallo BK, Layanan BK, Penelitian BK

\section{PENDAHULUAN}

Pendidikan yang bermutu di sekolah adalah pendidikan yang mampu membantu peserta didik mencapai standar akademis yang diharapkan sesuai dengan kondisi perkembangan diri yang sehat dan optimal. Pendidikan sebagai sarana optimalisasi dalam rangka mengaktualisasikan diri harus dapat mengarahkan individu untuk dapat mencapai tugas perkembangannya. Aktualisasi diri tersebut dapat dikembangkan dengan adanya layanan bimbingan konseling yang berorientasi kepada perkembangan diri terutama pada tugas perkembangan (developmental task) yang terkadang individu tidak mengetahui tugas perkembangannya sendiri. Bimbingan konseling sebagai bagian integral dari proses pendidikan memiliki tanggung jawab yang cukup besar dalam pengembangan kualitas manusia Indonesia yang telah diamanatkan dalam tujuan pendidikan nasional (Undang-Undang No 20 Tahun 2003).

Untuk mencapai perkembangan yang optimal, peserta didik tentunya membutuhkan berbagai peran dari pihak sekolah, termasuk guru bimbingan dan konseling (BK). Menurut Sukmadinata (2004), pemberian layanan bimbingan dan konseling dapat mengoptimalkan perkembangan diri anak-anak dan remaja karena beberapa alasan, salah satunya yaitu pemberian layanan bantuan dalam BK yang didahului oleh upaya pemahaman kemampuan, karakteristik, dan kesulitankesulitan yang dihadapi oleh peserta didik. Menurut Hurlock (Yusuf, 2009) pengaruh sekolah terhadap perkem bangan kepribadian anak sangat besar, karena sekolah merupakan subtitusi dari keluarga dan guru-guru merupakan substitusi dari orang tua.

Dinamika kehidupan yang bergerak cepat, kebutuhan informasi saat itu juga, membuat urgensi teknologi dan informasi dalam layanan bimbingan dan konseling dibutuhkan karena dapat 
memudahkan hubungan komunikasi antara konselor dan kliennya, sehingga pelayanan bimbingan dan konseling tidak lagi terbatas oleh ruang dan waktu dan konseling dapat dilakukan kapan saja dan dimana saja.Dalam era informasi, kecanggihan teknologi informasi dan komunikasi telah memungkinkan terjadinya pertukaran informasi yang cepat tanpa terhambat oleh batas ruang dan waktu (Dryden \& Voss, 2000). Dunia konseling harus bisa berkolaborasi dengan dunia teknologi dalam menghadapi dan mempertahankan keberadaan bimbingan dan konseling. Agar bisa bertahan dan diterima oleh masyarakat, maka bimbingan dan konseling harus dapat disajikan dalam bentuk yang efisien dan efektif. Salah satu penerapan teknologi informasi dalam pelayanan konseling diantaranya pada penyelenggaraan dukungan sistem. Dukungan sistem dapat berupa saranaprasarana, sistem pendidikan, sistem pengajaran, visi-misi sekolah dan lain sebagainya. Berbicara sarana dan prasarana, memasuki dunia globalisasi dengan pesatnya teknologi dan luasnya informasi menuntut dunia konseling untuk menyesuaikan dengan lingkungannya agar memenuhi kebutuhan masyarakat luas.

\section{METODE PENELITIAN}

Pelaksanaan penelitian dilaksanakan di SMA Negeri 6 Tasikmalaya. Dalam penelitian ini metode yang digunakan menggunakan metode kualitatif. Dimana akan di ukur mengenai tingkat kepuasan peserta didik setelah menerima layanan bimbingan dan konseling dengan menggunakan aplikasi Hallo BK. Penelitian dilaksanakan pada tanggal 5 Agustus 2021-2 September 2021. Berikut tabel kuisioner untuk mengevaluasi kualitas aplikasi Hallo BK sebagai media layanan bimbingan dan konseling berbasis teknologi informasi:

TABEL 1 KUISIONER

Aplikasi "Hallo Bk" Sebagai Layanan Bimbingan Dan Konseling Berbasis Teknologi Informasi Melalui Pengembangan Web

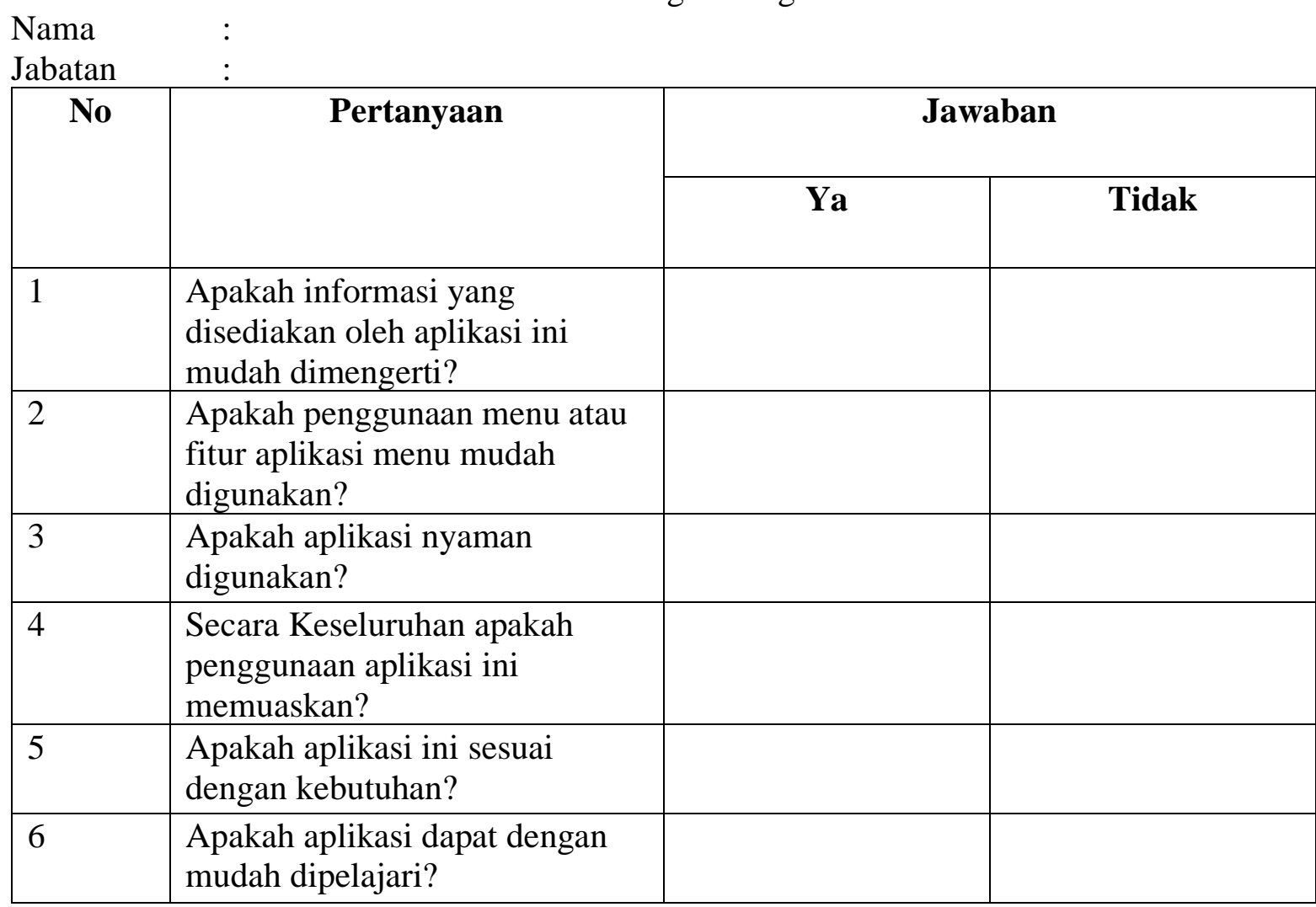


Vol. 1 No. 1 Juni 2021 e-ISSN : 2797-3344 P-ISSN : 2797-3336

\begin{tabular}{|l|l|l|l|}
\hline 7 & $\begin{array}{l}\text { Apakah aplikasi mudah } \\
\text { dioperasikan? }\end{array}$ & & \\
\hline 8 & $\begin{array}{l}\text { Apakah dapat dengan mudah } \\
\text { menghindari kesalahan dan } \\
\text { menggunakan aplikasi? }\end{array}$ & & \\
\hline 9 & $\begin{array}{l}\text { Apakah aplikasi bermanfaat } \\
\text { bagi pengguna? }\end{array}$ & & \\
\hline 10 & $\begin{array}{l}\text { Apakah tampilan menu dalam } \\
\text { aplikasi mudah untuk dikenali? }\end{array}$ & $\begin{array}{l}\text { Apakah aplikasi mempunyai } \\
\text { kemampuan dan fungsi sesuai } \\
\text { yang diharapakan? }\end{array}$ & \\
\hline
\end{tabular}

\section{HASIL DAN PEMBAHASAN}

\section{Hasil}

Berikut hasil layanan Bimbingan dan Konseling setelah menggunakan aplikasi Hallo BK:

Apakah Anda puas dengan kegiatan BK hari ini

141 jawaban
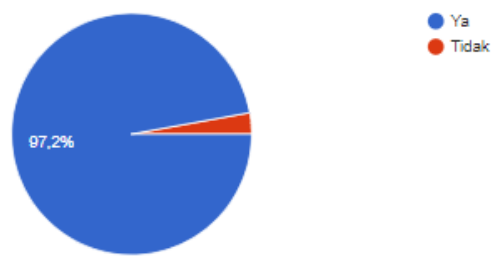

Diagram 1 Tingkat Kepuasan Peserta didik kelas XII terhadap Layanan Bimbingan dan Konseling dengan menggunakan aplikasi Hallo BK

Apakah Anda Puas dengan Pelayanan BK hari ini

47 jawaban

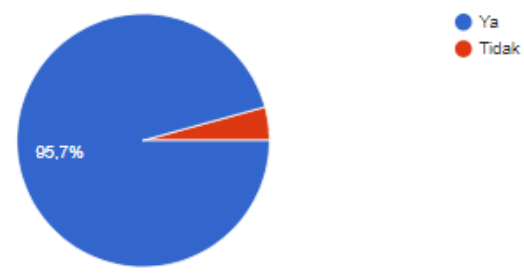

Diagram 2 Tingkat Kepuasan Peserta didik kelas XI terhadap Layanan Bimbingan dan Konseling dengan menggunakan aplikasi Hallo BK 
Apakah Anda Puas dengan pelayanan BK hari ini

62 jawaban

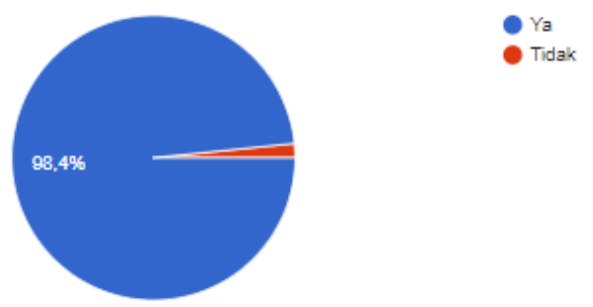

Diagram 3 Tingkat Kepuasan Peserta didik kelas X terhadap Layanan Bimbingan dan Konseling dengan menggunakan aplikasi Hallo BK

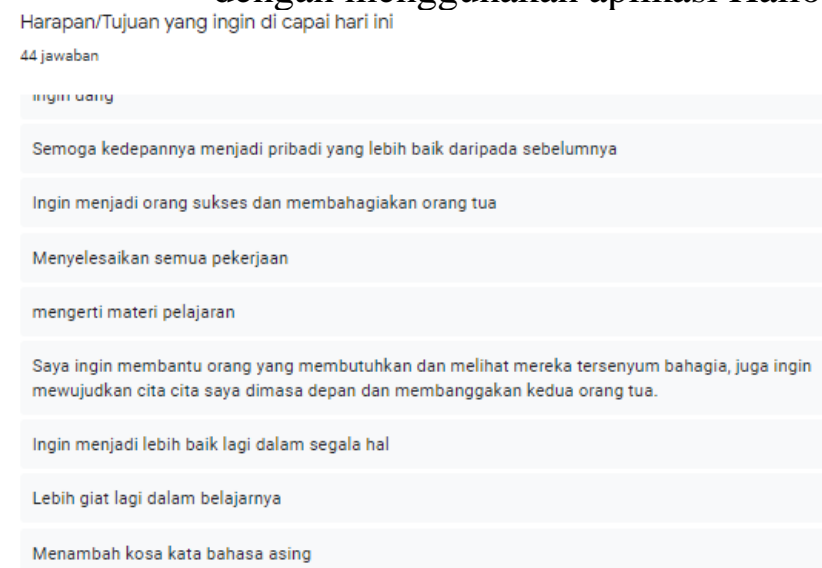

Diagram 4 Harapan Peserta didik setelah memperoleh layanan Bimbingan dan Konseling dengan menggunakan aplikasi Hallo BK

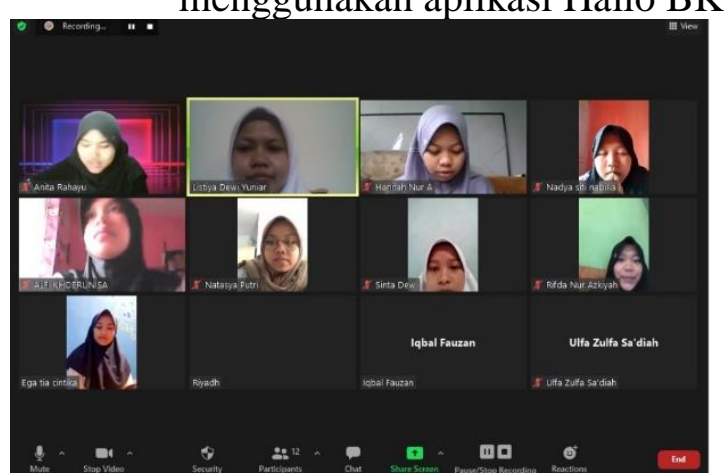

Gambar 1 Upaya tindak lanjut setelah analisis harapan dan tujuan peserta didik dalam penggunaan media layanan BK agar dapat lebih menunjang tugas perkembangan

Tabel 2 Hasil Kuisioner

\begin{tabular}{|l|l|c|c|}
\hline \multicolumn{1}{|c|}{ No } & \multicolumn{1}{|c|}{ Pertanyaan } & Ya & Tidak \\
\cline { 3 - 4 } & & 13 & 0 \\
\hline 1 & $\begin{array}{l}\text { Apakah informasi yang } \\
\text { disediakan oleh aplikasi ini } \\
\text { mudah dimengerti? }\end{array}$ & & \\
\hline
\end{tabular}


PAEDAGOGY : Jurnal Ilmu Pendidikan dan Psikologi

Vol. 1 No. 1 Juni 2021 e-ISSN : 2797-3344 P-ISSN : 2797-3336

\begin{tabular}{|c|c|c|c|}
\hline 2 & $\begin{array}{l}\text { Apakah penggunaan menu atau } \\
\text { fitur aplikasi menu mudah } \\
\text { digunakan? }\end{array}$ & 13 & 0 \\
\hline 3 & $\begin{array}{l}\text { Apakah aplikasi nyaman } \\
\text { digunakan? }\end{array}$ & 13 & 0 \\
\hline 4 & $\begin{array}{l}\text { Secara Keseluruhan apakah } \\
\text { penggunaan aplikasi ini } \\
\text { memuaskan? }\end{array}$ & 13 & 0 \\
\hline 5 & $\begin{array}{l}\text { Apakah aplikasi ini sesuai } \\
\text { dengan kebutuhan? }\end{array}$ & 13 & 0 \\
\hline 6 & $\begin{array}{l}\text { Apakah aplikasi dapat dengan } \\
\text { mudah dipelajari? }\end{array}$ & 13 & 0 \\
\hline 7 & $\begin{array}{l}\text { Apakah aplikasi mudah } \\
\text { dioperasikan? }\end{array}$ & 13 & 0 \\
\hline 8 & $\begin{array}{l}\text { Apakah dapat dengan mudah } \\
\text { menghindari kesalahan dan } \\
\text { menggunakan aplikasi? }\end{array}$ & 13 & 0 \\
\hline 9 & $\begin{array}{l}\text { Apakah aplikasi bermanfaat } \\
\text { bagi pengguna? }\end{array}$ & 13 & 0 \\
\hline 10 & $\begin{array}{l}\text { Apakah tampilan menu dalam } \\
\text { aplikasi mudah untuk dikenali? }\end{array}$ & 13 & 0 \\
\hline 11 & $\begin{array}{l}\text { Apakah aplikasi mempunyai } \\
\text { kemampuan dan fungsi sesuai } \\
\text { yang diharapakan? }\end{array}$ & 13 & 0 \\
\hline
\end{tabular}

Responden yang mengisi kuisioner terdiri dari:

3 Orang Peserta didik

3 Orang Guru BK

3 Orang Guru Mata Pelajaran

1 Orang Tua Peserta Didik

3 Orang Tim Manajemen Sekolah

\section{Pembahasan}

Seiring dengan perkembangan teknologi informasi dan komunikasi serta dampak perubahan yang bersifat komprehensif bagi masyarakat secara umum dan para peserta didik dalam dunia pendidikan secara khusus, membuat peneliti tergerak untuk melakukan terobosan atau inovasi sebagai solusi dalam menghadapi perubahan tersebut. Bimbingan konseling sebagai bagian yang integral dari pendidikan, atau sebagai layanan bimbingan dan konseling kepada peserta didik dengan program pemberian layanan bantuan kepada peserta didik dalam upaya mencapai perkembangannya yang optimal, melalui interaksi yang sehat dengan lingkungannya.

Pembuatan aplikasi Hallo BK pun merupakan inovasi yang membantu peserta didik serta guru BK dalam mengikuti perkembangan industri 4.0 dalam kehidupan modern yang semakin berkembang teknologi informasinya. Hal ini pun di dukung oleh pendapat Williams dan Sawyer (2003), yang mmengungkapkan mengenai teknologi informasi sebagai teknologi yang menggabungkan komputasi (komputer) dengan jalur komunikasi kecepatan tinggi yang membawa data, suara, dan video. Dari definisi di atas, nampak bahwa teknologi informasi tidak hanya terbatas 
pada teknologi komputer, tetapi juga termasuk teknologi telekomunikasi. Dengan kata lain bahwa teknologi informasi merupakan hasil konvergensi antara teknologi komputer dan teknologi telekomunikasi.

Setelah dilakukan layanan Bimbingan dan Konseling dengan menggunakan aplikasi Hallo BK diperoleh data mengenai tingkat kepuasan peserta didik serta tingkat kegunaan dan kelayakan aplikasi ini sebagai media berbasis teknologi informasi dalam memfasilitasi layanan Bimbingan dan Konseling di SMA Negeri 6 Tasikmalaya. Berdasarkan hasil penelitian maka terdapat 97,2\% peserta didik kelas XII yang merasa puas atas layanan yang diberikan. Untuk layanan yang diberikan kepada XII terdiri atas layanan karir serta konsultasi baik yang dilakukan oleh peserta didik maupun orang tua sebagai pencapaian karir peserta didik.

Selain itu tingkat kepuasan peserta didik kelas XI mencapai angka 95,7\%. Layanan yang diberikan untuk kelas XI mencakup layanan privado, sosial, akademik dan karir. Selain itu bagi peserta didik kelas X tingkat kepuasan mencapai angka 98,4\% yang tentunya lebih mengedepankan pada aspek pribadi dan akademik, terutama dalam hal adaptasi perpindahan dari SMP ke SMA. Sehingga dilihat dari angka-angka yang diperoleh sangat terlihat mengenai hasil yang sangat optimal yang dilakukan oleh peneiliti selama 5 Agustus 2021-2 September 2021.

Dengan adanya aplikasi Hallo BK ini pun dapat dilaksanakan layanan bimbingan dan konseling sebagai suatu proses pemberian bantuan kepada individu, yang dapat dilaksanakan melalui berbagai macam layanan yang tersedia pada aplikasi menú Hallo BK. Kegiatan pemberian layanan Bimbingan dan Konseling di masa pandemi Covid-19 dapat dilakukan melalui aplikasi Hallo BK. Dilihat dari data yang diperoleh melalui aplikasi Hallo BK pihak pengguna baik dari segi peserta didik, orangtua, guru mata pelajaran, tim manajemen, serta guru Bimbingan dan Konseling merasa terbantu dan di mudahkan dengan adanya aplikasi ini. Dari data tersebut sehingga dapat terlihat tujuan pembuatan aplikasi Hallo BK untuk memberikan kemudahan layanan bimbingan dan konseling dengan cara-cara yang lebih menarik, interaktif, dan tidak terbatas tempat, tetapi juga tetap memperhatikan azas-azas dan kode etik dalam bimbingan dan konselingpun dapat tercapai dengan baik.

Proses pemberian layanan Bimbingan dan Konseling yang dilakukanpun sejalan dengan konsep bimbingan yang diungkapkan oleh Prayitno \& Amti (2004) sebagai proses pemberian bantuan yang dilakukan oleh orang yang ahli kepada seseorang atau beberapa orang individu, baik anak-anak, remaja, maupun dewasa agar orang-orang yang dibimbing dapat mengembangkan kemampuan dirinya sendiri dan mandiri, dengan memanfaatkan kekuatan individu dan sarana yang ada dan dapat dikembangkan berdasarkan norma-norma yang berlaku. Hal ini tentunya dapat dilihat dari harapan dan tujuan yang di kemukakan oleh peserta didik setelah memperoleh layanan Bimbingan dan Konseling dengan menggunakan aplikasi Hallo BK.

Winkel (2007) mengemukakan bahwa tujuan pelayanan BK yaitu "supaya orangperorangan atau kelompok orang yang dilayani menjadi mampu menghadapi tugas perkembangan hidupnya secara sadar dan bebas mewujudkan kesadaran dan kebebasan itu dalam membuat pilihan-pilihan secara bijaksana serta mengambil beraneka tindakan penyesuaian diri secara memadai.

\section{KESIMPULAN}

Aplikasi Hallo BK dapat digunakan sebagai optimalisasi layanan Bimbingan dan Konseling di SMA Negeri 6 Tasikmalaya. Berdasarkan hasil penelitian maka terdapat 97,2\% peserta didik kelas XII yang merasa puas atas layanan yang diberikan. Untuk layanan yang diberikan kepada XII terdiri atas layanan karir serta konsultasi baik yang dilakukan oleh peserta didik maupun orang tua sebagai pencapaian karir peserta didik. Selain itu tingkat kepuasan peserta didik kelas XI mencapai angka 95,7\%. Layanan yang diberikan untuk kelas XI mencakup layanan privado, sosial, akademik 
dan karir. Selain itu bagi peserta didik kelas X tingkat kepuasan mencapai angka 98,4\% yang tentunya lebih mengedepankan pada aspek pribadi dan akademik, terutama dalam hal adaptasi perpindahan dari SMP ke SMA. Sehingga dilihat dari angka-angka yang diperoleh sangat terlihat mengenai hasil yang sangat optimal yang dilakukan oleh peneiliti selama 5 Agustus 2021-2 September 2021.

\section{DAFTAR PUSTAKA}

Dryden, Gordon dan Voss, Jeannette. Penerjemah: Nilandari, Ari. (2000). Revolusi Belajar (The Learning Revolution I dan III). Bandung: Kaifa.

Prayitno \& Erman Amti. (2004). Dasar-Dasar Bimbingan dan Konseling, Jakarta: Rineka Cipta

Sukmadinata, Nana Syaodih. (2004). Landasan Psikologi Proses Pendidikan. Bandung: PT. Remaja Rosdakarya.

Undang-Undang 2003 No 20, Sistem Pendidikan Nasional.

Williams dan Sawyer. (2003).Using Information Technology: A Practical. Introduction to Computers and Communications. London: Career Education.

W. S. Winkel \& M. M. Sri Hastuti. (2007). Bimbingan dan Konseling Di Institusi Pendidikan. Yogyakarta: Media Abadi.

Yusuf, Syamsu. 2009. Program Bimbingan dan Konseling Di Sekolah. Bandung: Rizqi Press. 